Mreached an annual sermon from the same text. It is certain that the sympathies of the public would be alienated; and if those hearers who are taken to task were to follow consistently the lesson inculcated, they would occupy them ielves entirely with objects of pecuniary gain instead of providing the discoveries which our manufacturers are so much in need of, or advancing learning by their contributions to the Philosothical Transactions.

W. N. HartLey

\section{Our Future Watches and Clocks}

IN reference to the note on this subject in NATURE (p. 36), it appears to me that to any radical change in dial-division there exist many objections, of more or less weight, over and above those already enumerated. In regard to-

(A) Striking the hours.-(I) It is said that "public clocks . could not go on to twenty-four." The same would apply to private clocks as well, as the higher numbers would be struck during the-to children and many others, sick or well-early hours of sleep, when greater disturbance from house clocks than at present occurs would be quite unendurable. The counteradvocacy of silent house clocks would scarcely meet the case.

(2) The alternative suggestion of "one stroke only at each hour" would do away with one important function of public clocks, that of marking to watchless people the exact hour. Persons abed, lonely watchers, and field-labourers, commonly depend upon the church clock for information which could only be acquired otherwise with much discomfort.

(B) The 24-division plan.--(3) That no diminution in "the angular motion of the hand" during any given time should be brought about seems most vital. The time of day is often obtained from far-distant clocks, and is even at present not easy to decipher readily, especially under circumstances of inadequate light or visual power.

(4) Similarly, in the case of any slight looseness in the hands -a commonly-neglected chronometric infirmity-it would be harder than ever to decide at a glance what hour is indicated.

(5) It will be observed that the adoption of this plan would almost necessitate half-minute arcs.

C) The double I2-division plan.-(6) Inasmuch as the presence of two concentric circles of figures of undiminished size would shorten the clear effective length of the hands, the arc subtended by the hourly angle "ould be diminished by much the same extent as in the previous plan $\left(B_{3}\right)$, and a similar objection would apply.

(7) The presence, in any form, of twenty-four symbols, in addition to the maker's name and the like, in the dial area, especially in ladies' time-pieces, would be eminently confusing, and restrictive of instantaneous decision as to what the time may be.

8. Even if, to obviate all this-a point suggested by the statement that "persons probably pay small attention to the figures"-a single circle of twelve conventional symbols, identical or not, such as a radial arrowhead, were adopted to indicate the a.m. and the p.m. hours in their turn, one would have to undergo the added mental labour of deciding the actual nimber of the hour.

(9) In any case the introduction of a "o" hour, unless we are to adopt railway phraseology, would be most awkward, and in the "double I 2-division plan" the transition at noon and midnight from one circle to the other would not be a simple sequence.

Finally, the question arises whether the now common timepieces, in which the hands are either replaced or supplemented by a series of peep-holes, wherein the minute, hour, and even week-day for the time being, are consecutively displayed, would not aid the introduction of the twenty-four hour system into rough general use. The main disadvantage of abolishing the hands is that one would lose an actual picture suggestive of the time which will elapse betwcen the present and any point in the near future. For all purposes for which closer chronometric accuracy is required, the above stumbling-blocks to change in dial-division, arising out of the pressing value in ordinary life of the ability to tell the time swiftly, and without undue mental effort, would be swept away.

88, Buckingham Road, N., November I9

As regards the practical question how clocks are to be made to strike if the dial is to show twenty-four hours, I have a sugbestion to make.
But firstly, the convenience of beginning the day at midnight is evident, as the early morning hours are those which it is most useful to have indicated to the ear, and our clocks may continute to strike from $\mathrm{I}$ a.m. to 6 as now.

The inconvenience of having to count any number of strokici above six is so great, and doing it so tedious, that most persons break down in attempting it with a slow-striking clock; and I think that there is a good deal to be said for the system, which obtains in some places where the hours are still reckoned as twenty-four, of beginning afresh at the end of every six hours, and denoting 7 and 13 as $1, \&$ c. This plan would make very little or no change.

But what I wished to suggest is: That clock-makers should make the clocks to beat the strokes in pairs; e.g. two strokes and a rest + two strokes and a rest + one stroke, would be 5 . This would be counted as easily as 3 . Moreover, there would be no occasion under ordinary circumstances to count the stroke: at all; whether the hour was odd or even would be all it was necessary to learn for one to know which hour it was of the twenty-four. One may, for instance, in the morning doubt whether it is ro or 11 , or whether it is 11 or 12 , but one rarely doubts whether it is Io or I2. And on the principle I recommend, the last stroke of the clock being single or double would decide the matter. One would not even have to attend to it. I contend that under the present system it is impossible for a person with only ordinary patience to discover whether a clock strikes $\mathrm{I}$ I or $\mathbf{I 2}$.

If you think anything of this suggestion, which I have always thought myself to be a fair solution of a difficulty, I shall be glad if you would insert it in your paper.

R. B.

\section{Lightning-Conductors}

In the Edinburgh Review of last July many of your readers will probably have noticed an article on "Lightning-Conductors," written somewhat strongly from the point of view of an advocate of the apparatus thus popularly designated. Perhaps a few words of comment on this paper from a rather different aspect may not be without interest to those who are able and willing to treat the subject with unprejudiced minds.

In the reviewer's narrative of the history of lightning-rods he omits all mention of Franklin's initial letter of September I, I 747-that letter in which the great discovery of the power of points is given to the world. But it is abundantly evident from his subsequent letters of 1749 and 1750 , in which he definitely forecasts the invention of rods, that it was to his knowledge of this power - and of this power alone - that he owed the idea of these instruments. In other words, his original conception was purely that of an apparatus for preventing the occurrence of a lightningstrolic at the place where the rod was erected. Now, if I am not mistaken, the reviewer from first to last never alludes to thi all-important function. It is true that Franklin himself afterwards fell in with the curious supposition that these rods acted as "conductors" of a stroke. But (so far as can be judged from his letters) this was not till September $\mathbf{7 5 3}$, at which time most of the European scientific men, themselves either ignorant or sceptical of the preventive power of points, had fully adopted the invention and had invested it with the theory, that has ever since been accepted, of its being a means of "conducting" past the building a stream of fiery matter (denoted as "electric fluid") descending from the clouds to the ground. Now it is evident that nothing can conduct the agency known by us as "lightning" without first being struck by it ; and it is also mani fest that, in order to be so struck, an object must present some "attraction" to the stroke. This attraction-this necessary first step to conduction-allowing for the nonce that an explosion such as constitutes a lightning-stroke can be conducted-is a matter that usually (and not unnaturally) is treated by those who believe in lightning-rods with some little reticence. I therefore think it is but fair to give credit to the reviewer for the open and honourable manner in which he enunciates his vicws of the true function of lightning-rods. IIe says (p. 40):"Conductcrs provided by engineering art are intend.d to bo struck, but struck in such a manner as to govern the lightning and to render the heaviest strokes harmless." There is no beating about the bush. He admits that his conductors are purposely fixed on a house in order to attract a stroke to that house with the view of afterwards rendering the effects of the explosion nugatory. Now the very essence of the opposition that has been made to the use of these conductors lies in this very fact of 